\title{
Soil bulk electrical resistivity and forage ground cover: nonlinear models in an alfalfa (Medicago sativa L.) case study
}

\author{
Roberta Rossi, ${ }^{1}$ Alessio Pollice, ${ }^{2}$ Gianfranco Bitella, ${ }^{3}$ Rocco Bochicchio, ${ }^{3}$ \\ Amedeo D'Antonio, ${ }^{4}$ Alaa Aldin Alromeed, ${ }^{3}$ Anna Maria Stellacci, ${ }^{5}$ Rosanna Labella, ${ }^{3}$ \\ Mariana Amato ${ }^{3}$
}

${ }^{1}$ Research Unit for the Extensive Animal Husbandry, Council for Agricultural Research and Analysis of Agricultural Economics, Bella (PZ); ${ }^{2}$ Department of Economics and Mathematics, University of Bari Aldo Moro, Bari; ${ }^{3}$ School of Agricultural, Forestry, Food and Environmental Sciences, University of Basilicata, Potenza; ${ }^{4}$ Department of Agricultural, Food and Forestry Policies, Campania Region, Naples; ${ }^{5}$ Research Unit for Cropping Systems in Dry Environments, Council for Agricultural Research and Analysis of Agricultural Economics, Bari, Italy

\begin{abstract}
Alfalfa is a highly productive and fertility-building forage crop; its performance, can be highly variable as influenced by within-field soil spatial variability. Characterising the relations between soil and forage-variation is important for optimal management. The aim of this work was to model the relationship between soil electrical resistivity (ER) and plant productivity in an alfalfa (Medicago sativa L.) field in Southern Italy. ER mapping was accomplished by a multi-depth automatic resistivity profiler. Plant productivity was assessed through normalised difference vegetation index (NDVI) at 2 dates. A non-linear relationship between NDVI and deep soil ER was modelled within the
\end{abstract}

Correspondence: Gianfranco Bitella, School of Agriculture, Forest, Food and Environmental Science, University of Basilicata, viale dell'Ateneo Lucano 10,85100 Potenza, Italy.

Tel: +39.0971.205385.

E-mail: gianfranco.bitella@gmail.com

Key words: Geophysical mapping; normalised difference vegetation index; alfalfa; soil spatial variability; generalised additive models.

Acknowledgements: this work was partially funded by the project IRRISOL sistema integrato di gestione irrigua differenziata tramite mappatura geoelettrica ad alta risoluzione. PSR Regione Campania 2007-2013 mis. 124. DRD n. 215 del 07/06/2013. Codice CUP B55C11003040007. The authors wish to thank the farmer Mr Felice Parisi, for his logistic support.

Conference presentation: SIA XLIII Congress, Pisa, 2014.

Received for publication: 26 December 2015.

Revision received: 13 May 2015.

Accepted for publication: 17 May 2015.

(C) Copyright R. Rossi et al., 2015

Licensee PAGEPress, Italy

Italian Journal of Agronomy 2015; 10:647

doi:10.4081/ija.2015.647

This article is distributed under the terms of the Creative Commons Attribution Noncommercial License (by-nc 3.0) which permits any noncommercial use, distribution, and reproduction in any medium, provided the original author(s) and source are credited. framework of generalised additive models. The best model explained $70 \%$ of the total variability. Soil profiles at six locations selected along a gradient of ER showed differences related to texture (ranging from clay to sandy-clay loam), gravel content (0 to 55\%) and to the presence of a petrocalcic horizon. Our results prove that multi-depth ER can be used to localise permanent soil features that drive plant productivity.

\section{Introduction}

Alfalfa (Medicago sativa L.) is one of the most productive forage legumes in terms of feed protein and quality of forage, it is widely used in rotation as a fertility-building crop due to its high biological nitrogen fixation (BNF) capacity. Within field spatial variability plays a key role in BNF rates, yield and quality of forage, and hence must be considered in calculating N-budgets (Nykänen et al., 2008) as well as for yield forecasting. Over the last decade geophysical sensors based on the non-destructive measurement of soil electrical conductivity (or its inverse resistivity) have been extensively used in precision agriculture (Kitchen et al., 2005; Moral et al., 2010; Peralta and Costa, 2013). Electrical resistivity (ER) can be used as a proxy of relevant soil properties (Samouelian et al., 2005) such as clay content (Buvat et al., 2014), gravel lenses (Tetegan et al., 2012) and bulk density (Besson et al., 2004). Multi-depth continuous resistivity profiling has been used to delineate permanent soil features at farm scale (Besson et al., 2010; André et al., 2012; Bouvat et al., 2014). Deep soil variability might be relevant for deep-rooted perennials such as alfalfa that can fuel regrowth by relying on residual deep soil water reserves in late spring (Annicchiarico et al., 2011). In order to profitably use sensor-based soil information in agricultural management, however, ER variability must be related to crop growth. As argued by Shatar and McBratney (1999) soil uniform zones are not necessarily yield uniform zones and nonlinearity often occurs. Among empirical modelling techniques generalised additive models (GAMs) are well suited to represent non-linearity that might exist in soil-yield relationships (Shatar and McBratney, 1999) as well as between ancillary information and soil properties (Bishop and McBratney, 2006). In this work we surveyed within-farm plant and soil variability by coupling a multi-depth automatic resistivity profiler (ARP) (Geocarta, Paris, France) and a radiometric sensor (Greenseeker ${ }^{\mathrm{TM}}$ ) derived normalised difference vegetation index (NDVI). The objective of the analysis was to test the suitability of multi-depth resistivity profiling for identifying soil features relevant 
for plant productivity. Based on the relationship between resistivity and NDVI modelled by a GAM, a limited number soil sampling locations was selected for ground-truth validation.

\section{Materials and methods}

\section{Site description}

The experiment was conducted in a 7-ha alfalfa (Medicago sativa $\mathrm{L}$. cv. Altiva) stand in Palomonte (SA, Italy) (N $40.613952^{\circ} \mathrm{E} 15.303264^{\circ}$ ) at $210 \mathrm{~m}$ asl South Italy. The soil was classified as a Typic Eutrudept fine, mixed, thermic Calcaric Cambisols (Soil Survey Staff, 1999; IUSS Working Group WRB, 2006).

The average soil texture within the first $0.5 \mathrm{~m}$ layer was $41.29 \%$ sand, $17.14 \%$ silt, $41.57 \%$ clay average soil organic matter content was $26 \mathrm{~g} \mathrm{~kg}^{-1}$. The stand was planted in November 2011 in rows at a seeding rate of $40 \mathrm{~kg} \mathrm{ha}^{-1}$, was grown in rainfed conditions and cut at an average rate of 3 cuts/y.

\section{Automatic resistivity profiling}

In this study, we carried out measurements on the whole 7 ha field using the on-the-go multi-depth resistivity meter (ARP@, Geocarta) (Rossi et al., 2013). Rolling electrodes towed across the field enabled resistivity (ER) to be measured simultaneously at three different depths that correspond to the distance between receiving wheels $(\mathrm{V} 1=0.50 \mathrm{~m}, \mathrm{~V} 2=0.70 \mathrm{~m}, \mathrm{~V} 3=1.7 \mathrm{~m})$. Data were real-time referenced by differential global positioning system (DGPS). Data were collected on 18 June 2013 along parallel transects at $6 \mathrm{~m}$ apart. A total number of 122,460 measurements was taken. The entire area was surveyed in about 40 minutes at an average speed of $9 \mathrm{~km} \mathrm{~h}^{-1}$. The average soil water content, within the first $0.5 \mathrm{~m}$ soil layer, at the time of soil sampling was $27.40 \%$.

\section{Ground cover}

Alfalfa ground cover was measured by a handheld NDVI optical sensor GreenSeeker ${ }^{\mathrm{TM}}$ on-the-go on 11 September 2013 and $1^{\text {th }}$ November 2013. A third acquisition was carried out on 21 October 2014 (data not shown). The sensor was mounted on a platform and towed by an all-terrain vehicle while data were real-time referenced by DGPS. The system was towed across the field along parallel transects in a serpentine feature using the same distance $(6 \mathrm{~m})$ between transects that was used by the ARP system. Following manufacturer's instructions operating height was kept at $1 \mathrm{~m}$ from the ground and the sensor head was oriented in-line with the target. The total of number of measurements, for each acquisition, ranged around 210,630 .

\section{Statistical analysis}

The objective of the analysis was to model the relationship between NDVI and ER. Sensor data were checked for normality and for the presence of outliers. Values above $9^{\text {th }}$ percentile were considered outlying observations and were removed. Data were interpolated onto the same $5 \times 5 \mathrm{~m}$ grid using the inverse distance algorithm. To evaluate the effects of geomorphology, point elevation data were rasterised onto the $5 \times 5 \mathrm{~m}$ grid and slope was calculated and used as explanatory variable. A non-linear relationship between NDVI and ER was modelled using GAM. The GAM was fitted by penalised likelihood maximisation with the function gam in the R library mgcv) (Wood, 2006). Smoothing parameters were automatically chosen to minimise an internal Generalised Cross Validation criterion. Models were checked for viola- tion of independence, variance homogeneity and residuals normality by graphical outputs. Starting from a set of candidate models, built having NDVI as a response variable and following a stepwise variable selection process, the final model was selected by comparing the Akaike information criterion (AIC) and the Bayesian information criterion (BIC). Both criteria give a measure of the model goodness of fit penalising for model complexity to control over-fitting (Zuur et al., 2009). Statistical analyses were accomplished within the $\mathrm{R}$ environment (version 3.0.2; R Development Core Team, 2013).

\section{Soil sampling}

Based on the non-linear relationship between ER and NDVI, depicted by the GAM model (see statistical analysis section above), ground-truth calibration of ARP sensor data was carried out by selecting six sampling sites along a gradient of resistivity. Sampling sites were located in areas of high, medium and low resistivity and in areas characterised by ER threshold values where soil-plant relationship changed. On 18 April 2014, 6 trenches were excavated down to two meters depth. Pedological description was carried out according to the regional guidelines for pedological surveys (Campania Region, 2014). Sixteen soil samples were collected along the profile and the following parameters were lab determined: soil texture (hydrometer), soil organic matter (Walkley-Black methodology), 42 samples were collected to measure gravimetric water content. Root colonisation below $1.20 \mathrm{~m}$ was estimated by counting the number of visible roots in a rectangle of the trench wall of $100 \mathrm{~cm}$ width $\times 80 \mathrm{~cm}$ height) (Walkley and Black, 1934).

\section{Results and discussion}

In our data both resistivity (ER) and NDVI showed a large structured variability across the field. ER values ranged from 3.7 to $64 \mathrm{Ohm}$ m with three layers displaying a strong linear correlation $(r=0.95$ between $V 1$ and V2, 0.92 between V2 and V3 and 0.83 between V1 and V3). The coefficient of variation of ER, increased with depth rising from $40 \%$ in V1 to $55 \%$ in V3. The NDVI at the first date (September) ranged between 0.33 and 0.89 while in November it approached saturation with values comprised between 0.71 and 0.90 . The two readings, showed consistency in spatial patterns and were linearly correlated $(r=0.55)$. A similar pattern was also visible on NDVI acquired a year later (November 2014, data not shown). At a visual analysis, the spatial pattern of NDVI and ER (respectively Figure 1B and A), were similar: many high resistivity (red) areas corresponded to areas of low NDVI, and low resistivity features (blue) corresponded to areas of high NDVI. Exploratory analysis therefore showed that NDVI was negatively correlated with resistivity measured in all of the three layers but mostly with the third layer $(\mathrm{r}=-0.49)$, the relationship though was non-linear and was therefore modelled with a GAM (depicted in Figure 1B-left and Table 1). The smoothing function picked up a threshold value of resistivity, approximately corresponding to $12-0 \mathrm{hm} \mathrm{m}$, above which NDVI declined following an exponential decay with increasing resistivity. Below this threshold, however, although data are very scattered, there was a weak $(\mathrm{r}=0.21)$ but significant $(\mathrm{P}<0.05)$ positive correlation between NDVI and ER, indicating that in areas of very low resistivity NDVI decreases. To model the effect of the geomorphology the terrain variable slope was added as explanatory variable, moreover a smooth function of the geographic coordinates was included to account for the non-linear spatial trend that was detected in the map of residuals. The best model, chosen comparing both AIC and BIC criteria was the one explaining NDVI as a non-linear function of resistivity measured at the deepest layer, plus a 
linear additive effect of the slope and a non-linear trend of the coordinates (Table 1). This model explained $70 \%$ of the total NDVI variability, model check showed uncorrelated residuals and a high correlation between observed and predicted values. Based on gradients of ER, six trenches were excavated in the field. All sites showed distinct characteristics consistent with both ER and NDVI values: texture in the 0-0.5 $\mathrm{m}$ layer ranged from sandy-clay-loam to clay (Figure 1C-left), and in one trench (A3) a large rock fragments content was found (55\%). Root counts (RC) below $1.2 \mathrm{~m}$ also differed between profiles (Figure 1Cright). The highest values of resistivity $(>50 \mathrm{Ohm} \mathrm{m}$ ) were measured in correspondence of trench A4 and A5 where a petrocalcic horizon below $0.5 \mathrm{~m}$ was found. Trench A5 corresponds to the lowest $\mathrm{RC}$ value and a low NDVI (0.5). At this site the presence of a hardpan, coupled with a low water content (14\% on average at the time of measure-
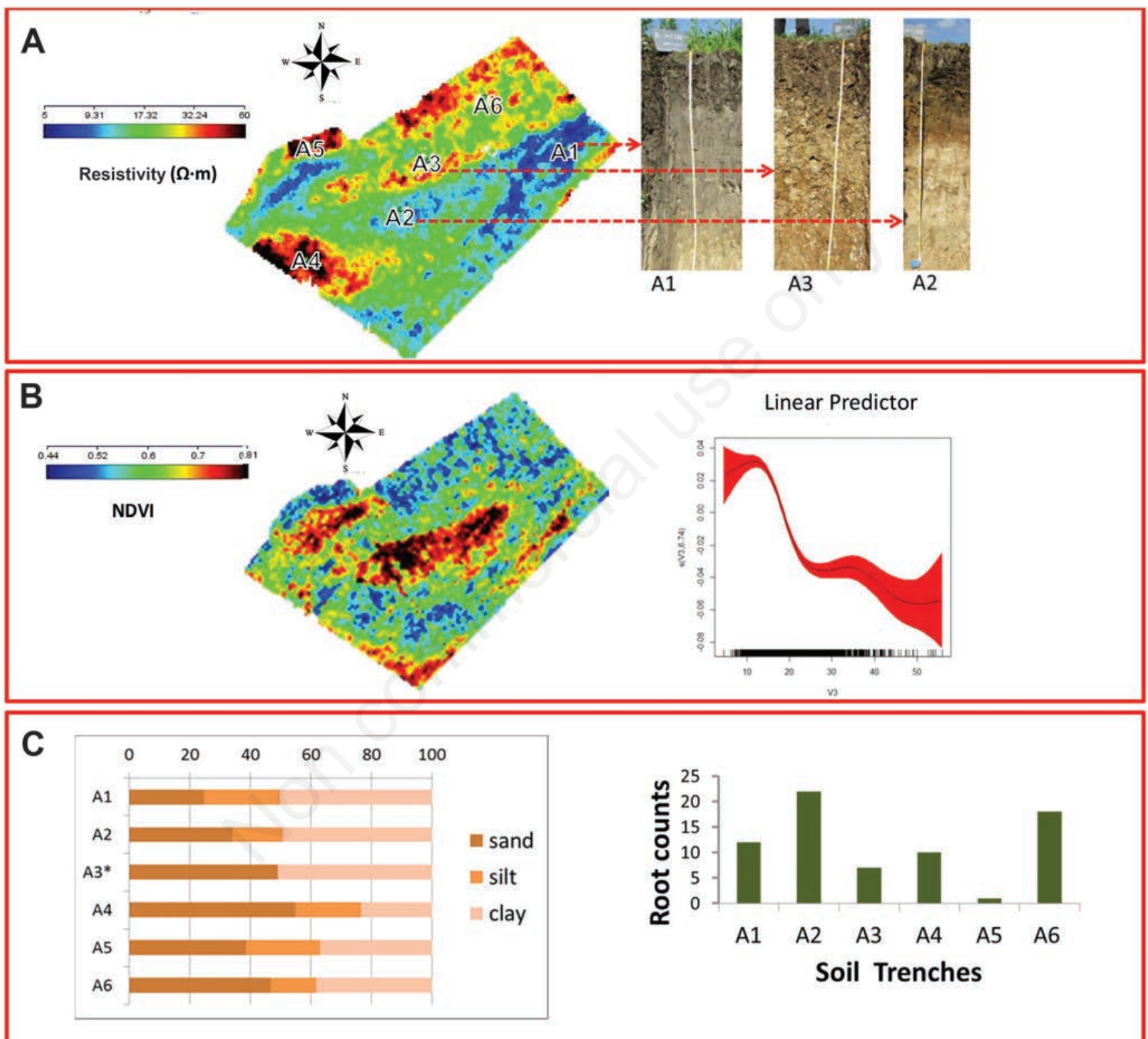

Figure 1. Caption report. A) Left: Field map electrical (ER) (Ohm m) measured in the third layer (V3). ER values range from 5 to 60 $\mathrm{Ohm} \mathrm{m}$, high values are displayed in red shade while blue shade depicts low values. The trenches position and number is indicated by black letters, red dotted arrows indicate (right side) the corresponding selected soil trenches pictures: A1, A2, A3. B) Left: map of the normalised difference vegetation index (NDVI) measured on the first date (range: $0.44-0.81$ ), red shade indicate high values and blue shade depict low values. Right: Scatterplot of the estimated smoother for the generalised additive model. The solid line is the estimated smoother, the red shaded regions are the $95 \%$ point-wise confidence bands. The horizontal axis shows the V3 ER (Ohm $\mathrm{m}$ ) and the vertical axis is the contribution of the smoother to the fitted values. The smoother is centred around 0 . C) Left: bar plot of soil texture measured in the top-layer $(0-0.5 \mathrm{~m})$. The values are referred to the fine earth, in trench $\mathrm{A3}$ (asterisked) a $55 \%$ of rock fragments was measured. Right: bar plot of root counts on a rectangle on the trenches walls of $100 \mathrm{~cm}$ width $\times 80 \mathrm{~cm}$ height below $1.2 \mathrm{~m}$ depth. 
Table 1. Summary statistic of the best fitted generalised additive model. Alfalfa normalised difference vegetation index was estimated as a function of one parametric term (terrain slope $=S \mathrm{~L}$ ) and two smooth terms $(\mathrm{s})$ : a smoothing function of the electrical resistivity (ER) $(\mathrm{Ohm} \mathrm{m})$ of the third layers (ER V3) and a non-linear trend of the geographic coordinates (easting + northing).

\begin{tabular}{|c|c|c|}
\hline \multicolumn{3}{|c|}{ Fitted model } \\
\hline \multicolumn{3}{|c|}{ NDVI $=\alpha+\beta_{1}\left(\right.$ SL) $+s\left(\right.$ ER V $\left._{3}\right)+s$ (easting + northing) } \\
\hline \multicolumn{3}{|c|}{ Explanatory variables } \\
\hline Parametric terms & Estimated coefficients & P-value \\
\hline Intercept $(\alpha)$ & 0.619 & $<0.001$ \\
\hline Terrain slope (SL) -0.002 & $<0.001$ & \\
\hline $\begin{array}{l}\text { smooth terms } \\
s \text { (easting + northing) } \\
s\left(E R_{V_{3}}\right)\end{array}$ & $\begin{array}{c}\text { Estimated degrees of freedom } \\
28.653 \\
7.692\end{array}$ & $\begin{array}{l}\text { P-value } \\
<0.001 \\
<0.001\end{array}$ \\
\hline Deviance explained & $\begin{array}{l}\text { Model performance } \\
\qquad \mathbf{R}^{2}-\text { Adj }\end{array}$ & nobs \\
\hline $70.30 \%$ & 0.698 & 2574 \\
\hline
\end{tabular}

NDVI, normalised difference vegetation index; ER, electrical resistivity.

ments), might have constituted an impenetrable layer for roots. ER sensitivity to the presence of hardpan was also reported by other authors (Tabbagh et al., 2000; Priori and Fantappi, 2013). As mentioned, a petrocalcic horizon of high resistivity was also found in trench $\mathrm{A} 4(\mathrm{ER}=56.4 \mathrm{Ohm} \mathrm{m})$; this area however is situated at the bottom of the field where drainage channels converge (at the time of measurements below $1.20 \mathrm{~m}$ there was a water content of $22 \%$ ). The NDVI was slightly higher (0.56) and also a higher RC was recorded. Roots in this trench penetrated the hardpan colonising plane of weakness creating large bio-pores. The lowest ER (7 Ohm $\mathrm{m})$ was measured in trench A1 where also low NDVI ( 0.5 on average) was measured. Remarkably this profile showed hydromorphic characteristics supporting the results of the GAM that indicated the NDVI is low when ER decreases below 12Ohm $\mathrm{m}$. In our survey resistivity proved to be correlated to permanent soil features, and this is consistent with other studies (Besson et al., 2010; Andrè et al., 2012). ER variability was related to NDVI, but nonlinearly, and the use of a GAM helped identifying threshold values where soil-plant relationship changed. A significant correlation between ER and plant variability was also found by Rossi et al. (2013) in vine, supporting the hypothesis that perennials tend to develop persistent spatial pattern following soil variability. Plant variability was mostly correlated with the ER below $1 \mathrm{~m}$ indicating that the stand might be mostly relying on resources in deep strata. Mapping the presence of hardpans could be used to optimise the choice of the cultivar in precision planting applications. Research on drought-resistant alfalfa varieties has shown that the root system size was a trait expressed consistently by cultivars growing in different environments regardless of its adaptive value (Annicchiarico et al., 2007). A large root system would be beneficial in soils with deep water reserves, whereas on shallow soil, in water-limited environments, water must be dried up in a conservative way: in this case a favourable root trait might be a reduced root hydraulic conductivity (Richards and Passioura, 1989). Deep layers variability is relevant for perennials but is also important for crops following alfalfa. Gaiser and co-authors (2012) found that water extraction from deep soil layers $(90-105 \mathrm{~cm})$ was significantly higher when wheat followed alfalfa compared to wheat sown after chicory and fescue, indirect evidence that wheat could have extended its root zone by colonising bio-pores created by alfalfa. Detailed information on root zone spatial variability can also be used in crop models, which rarely take into account rooting depth variability, even though neglecting it, leads to substantial biases in model predictions (Raza et al., 2013).

\section{Conclusions}

ER was correlated to the presence of permanent soil features also related to plant variability. Highest resistivity values matched areas where a petrocalcic horizon was found, while lowest values $(<12 \mathrm{Ohm}$ $\mathrm{m}$ ) corresponded to a clayey hydromorphic soil. The highest correlation between NDVI and ER of the third layer supported the hypothesis that alfalfa was relying on resources in deep strata, and this was also corroborated by the persistent spatial pattern along the growing season. Multi-depth soil information is important for deep rooted perennials such as alfalfa and might be considered also for following crops that can access subsoil through pre-existing bio-pores network.

\section{References}

André F, Van Leeuwen C, Saussez S, Van Durmen R, Bogaert P, Moghadas D, Lambot S, 2012. High-resolution imaging of a vineyard in south of France using ground-penetrating radar, electromagnetic induction and electrical resistivity tomography. J. Appl. Geophys. 78:113-22.

Annicchiarico P, 2007. Lucerne shoot and root traits associated with adaptation to favourable or drought-stress environments and to contrasting soil types. Field Crop. Res. 102:51-9.

Annicchiarico P, Pecetti L, Abdelguerfi A, Bouizgaren A, 2011. Adaptation of landrace and variety germplasm and selection strategies for lucerne in the Mediterranean basin. Field Crop. Res. 120:283-91.

Besson A, Cousin I, Bourennane H, Nicoullaud B, Pasquier C, Richard G, Dorigny A, King D, 2010. The spatial and temporal organization of soil water at the field scale as described by electrical resistivity measurements. Eur. J. Soil Sci. 61:120-32.

Besson A, Cousin I, Samouëlian A, Boizard H, Richard G, 2004. Structural heterogeneity of the soil tilled layer as characterised by 2D electrical resistivity surveying. Soil Till. Res. 79:239-49.

Bishop TFA, McBratney AB, 2006. A comparison of prediction methods for the creation of field-extent soil property maps. Geoderma 103:149-60.

Buvat S, Thiesson J, Michelin J, Nicoullaud B, Bourennane H, Coquet Y, Tabbagh A, 2014. Multi-depth electrical resistivity survey for 
mapping soil units within two 3ha plots. Geoderma 232-234:317-27.

Campania Region, 2014. Dipartimento per le Politiche Agricole Alimentari e Forestali - Norme tecniche per la valutazione della capacita d'uso dei suoli mediante indagine pedologica sito specifica. Available from: http://www.agricoltura.regione.campania.it/rinnovabili/norme_tecniche_capacita_uso_suolo_1_2.pdf

Gaiser T, Perkons U, Martin P, Uteau D, Peth S, Kautz T, Köpke U, 2012. Field Crops Research Evidence of improved water uptake from subsoil by spring wheat following lucerne in a temperate humid climate. Field Crop. Res. 126:56-62.

IUSS Working Group WRB, 2006. World reference base for soil resources 2006. FAO, Rome, Italy, pp 128.

Kitchen NR, Sudduth KA, Myers DB, Drummond ST, Hong SY, 2005. Delineating productivity zones on claypan soil fields using apparent soil electrical conductivity. Comput. Electron. Agric. 46:285-308.

Moral FJ, Terrón JM, Silva JR M, 2010. Delineation of management zones using mobile measurements of soil apparent electrical conductivity and multivariate geostatistical techniques. Soil Till. Res. 106:335-43.

Nykänen A, Jauhiainen L, Kemppainen J, Lindström K, 2008. Fieldscale spatial variation in yields and nitrogen fixation of clovergrass leys and in soil nutrients. Agric. Food Sci. 17:376-93.

Peralta NR Costa JL, 2013. Delineation of management zones with soil apparent electrical conductivity to improve nutrient management. Comput. Electron. Agric. 99:218-26.

Priori S, Fantappi M, 2013. Using the ARP-03 for high-resolution mapping of calcic horizons. Int. Agrophyis. 27:313-21.

Raza A, Friedel JK, Moghaddam A, Ardakani MR, Loiskandl W, Himmelbauer M, Bodner G, 2013. Modeling growth of different lucerne cultivars and their effect on soil water dynamics. Agric. Water Manage. 119:100-10.

Richards R, Passioura J, 1989. A breeding program to reduce the diameter of the major xylem vessel in the seminal roots of wheat and its effect on grain yield in rain-fed environments. Austr. J. Agric. Res. 40:943.

Rossi R, Amato M, Pollice A, Bitella G, Gomes JJ, Bochicchio R, Baronti S, 2013. Electrical resistivity tomography to detect the effects of tillage in a soil with a variable rock fragment content. Eur. J. Soil Sci. 64:239-48.

Samouëlian A, Cousin I, Tabbagh A, Bruand A, Richard G, 2005. Electrical resistivity survey in soil science: a review. Soil Till. Res. 83:173-93.

Shatar T, McBratney A, 1999. Empirical modelling of relationships between sorghum yield and soil properties. Precision Agric. 1:249-76.

Soil Survey Staff, 1999. Soil taxonomy: a basic system of soil classification for making and interpreting soil surveys. 2nd ed. USDA Agric. Handb. 436. U.S. Gov. Print. Office, Washington, DC, USA.

Tabbagh A, Dabas M, Hesse A, Panissod C, 2000. Soil resistivity: a non-invasive tool to map soil structure horizonation. Geoderma 97:393-404.

Tetegan M, Pasquier C, Besson A, Nicoullaud B, Bouthier A, Bourennane H, Cousin I, 2012. Field-scale estimation of the volume percentage of rock fragments in stony soils by electrical resistivity. Catena 92:67-74.

Walkley A, Black IA, 1934. An examination of the Degtjareff method for determining organic carbon in soils: effect of variations in digestion conditions and of inorganic soil constituents. Soil Sci. 63:251-63.

Wood S, 2006. Generalised additive models: an introduction with $\mathrm{R}$. Chapman \& Hall/CRC, Boca Raton, FL, USA.

Zuur A, Ieno EN, Walker N, Saveliev AA, Smith GM, 2009. Mixed effects models and extensions in ecology with R. Springer Science \& Business Media, Berlin, Germany. 